AC 2012-5564: TWO-SEMESTER AGILE SYSTEMS ENGINEERING DESIGN COURSE: INVESTIGATION AND EXPLORATION OF "IMMERSIVE', TRAINING TECHNOLOGIES

\author{
Andrew Bodenhamer, Missouri University of Science and Technology \\ Dr. Ivan G. Guardiola, Missouri University of Science \& Technology \\ Dr. Steven Michael Corns \\ Dr. Cihan H. Dagli, Missouri University of Science \& Technology
}

Cihan Dagli is a professor of engineering management and systems engineering, and Affiliated Professor of electrical and computer engineering at the Missouri University of Science and Technology. He received B.S. and M.S. degrees in industrial engineering from the Middle East Technical University and a Ph.D. in applied operations research in large scale systems design and operation from the University of Birmingham, United Kingdom, where from 1976 to 1979 he was a British Council Fellow. His research interests are in the areas of systems architecting and engineering, system of systems, smart engineering system design, and computational intelligence: neural networks-fuzzy logic-evolutionary programming. Dagli's contributions to systems engineering began in 1979 with his Ph.D. dissertation at the University of Birmingham, Birmingham, England, titled "A Methodology for Solving the Long Term Operational Problems of the Lower Firat Basin in Turkey." This interdisciplinary topic lead to a mathematical programming model-based approach for the solution of this complex water resources system problem. In the intervening years, he continued work on large scale system based problems. He has expertise in modeling architectures for complex engineering systems such as transportation, infrastructure, water resources, and energy distribution using computational intelligence techniques $\mathrm{He}$ is the Founder of the Missouri S\&T's system engineering graduate program. Dagli is the Director of the Smart Engineering Systems Laboratory and a Senior Investigator in the DoD Systems Engineering Research Center-URAC. He is an INCOSE Fellow 2008 and IIE Fellow 2009. He has been the PI, Co-PI, or Director of 46 research projects and grants totaling more than $\$ 29$ million from federal, state, and industrial funding agencies Dagli is the Area Editor for Intelligent Systems of the International Journal of General Systems, published by Taylor and Francis, and Informa, Inc. He has published more than 350 papers in refereed journals and proceedings, 21 edited books, and has been cited 900 times. He has consulted with various companies and international organizations including the Boeing Company, AT\&T, John Deere, Motorola, U.S. Army, UNIDO, and OECD. 


\section{Two-semester Agile Systems Engineering Design Course: Investigation and Exploration of "Immersive" Training Technologies}

\section{Introduction}

The teaching of systems engineering is a daunting task that involves the development of curriculum capable of teaching students the systems engineering process, the design aspects of engineering, and the interdisciplinary knowledge of a variety of fields. Design is widely considered to be the central or the major distinguishing activity of engineering ${ }^{1}$. Design can be considered as the center of system engineering, in which engineers employ an interdisciplinary approach to design effective solutions to meet social needs. However, systems engineering requires that traditional academic boundaries be crossed and intertwined with other fields of engineering as well as business, socio-political, and other disciplines that clearly interacts with or are directly affected by the system under consideration. Systems engineering requires different design thinking, as it requires in depth knowledge often beyond the traditional engineering classification boundaries. For example, an electrical engineer must also in many cases have knowledge of software engineering, or safety engineering when designing a cell phone circuit. In Dym et al. ${ }^{2}$, it is proposed that there are many informative approaches to characterizing design thinking, which attribute and highlight the skills often associated with good designers, namely, the ability to:

a. Tolerate ambiguity that shows up in viewing design as inquiry or as an iterative loop of divergent-convergent thinking

b. Maintain sight of the big picture by including systems thinking and systems design

c. Handle uncertainty

d. Make decisions

e. Think as part of a team in a social process

f. Think and communicate in several languages of design.

Hence, in an effort to increase the effective teaching of systems engineering and design of complicated systems we sought to increase these efforts by developing a capstone course. The capstone course approach to design engineering education has evolved over the years from "made up" projects devised by faculty to industry-sponsored projects where companies provide "real" problems, along with the expertise and financial support ${ }^{3}$. Following this proven and widely employed method of teaching a capstone course, a two-course sequence was developed at Missouri S\&T. This sequence sought to increase the before mentioned list of skills and characteristics that make good design engineers. The first course "Systems Engineering Analysis" sought to incorporate the skills a, b, and e. The second course "Physical Artifact Creation and Validation" incorporated the skills in $\mathrm{c}, \mathrm{d}$, and $\mathrm{f}$. The design work that is conducted in the first course is carried over to the second course in the following semester. However, both courses are held every semester, such that one design is being developed while a different related 
design is being realized. This course layout is by necessity an asynchronous execution of what would normally be a concurrent product development. This presents both the challenges of uncertain interface design but also the opportunity to expose the students to a limited product spiral development strategy.

\section{The Gap}

The push to realize a consistent pedagogy for systems engineering has been a long and well-discussed problem within academic literature. Samson and Lowery ${ }^{4}$ provide a discussion on how to increase systems engineering within regular education is discussed and they provide and outlined a senior systems engineering course. They also discuss those systems methodology should be incorporated throughout the four-year degree program. Samson and Lowery outline that all students prior to enrolling in their respective engineering department's senior capstone design course should take a systems engineering course. Samson and Lowery provide an outline of what such course should have as its main learning objectives, which are: 1). Review of the Systems Engineering model. 2). Relationship of previous course work to systems engineering. 3). Systems engineering as a foundation for the capstone design course. 4). General discussion of Decision making under certainty, under uncertainty, and under risk, and with single and multiple criteria. 5.) Linear programming. 6). CPM/PERT. 7). Decision making under uncertainty. 8). Decision Making under Risk. 9). Multi-Criterion Decision Making. In a more elaborate discussion about what is systems engineering education and what it should seek to fulfill, Sage ${ }^{5}$ elaborates that students should learn about the process of design and how to partition complicated problems into workable problems without losing information of the overall system. Hence, the problem continues to elude academics as due to the interdisciplinary nature of systems engineering it is difficult to create a learning environment, which supplies rigor in the application of systems engineering processes within the curriculum.

Hence, this paper discusses the efforts to create a capstone design course that can introduce the students to systems engineering, while emplacing a sustainable teaching practice that seeks to fulfill all the major points highlighted by Samson and Lowery. Following the frameworks proposed by Sage and Samson a two course systems engineering capstone course was designed with the first course goals associated with familiarizing the student to the systems engineering process and tools. The second course sought to enforce the first course by presenting the students with a holistic and rigorous application of decision making with actual real-world data. The paper will briefly discussed some of the student tasks within each course and how they seek to present the student with a different educational experience that makes use of systems engineering processes and tools.

\section{Course Structure}

The capstone is comprised of two courses, which are taken in sequential order. First, the students enroll in Systems Engineering 368 and upon its completion follow up by enrolling in Systems Engineering 468. The following is a brief synopsis of the "Immersive Training System" development project and examples of tasks presented to the students in each course. 
The overarching project for these courses was a sponsored project by the Dept. of Defense, Office of Systems Directorate through the Systems Engineering Research Center University Affiliated Research Center SERC-UARC formed by 20 universities. Missouri University of Science and Technology is one of the participating universities. The project's primary focus was to derive a solution to meet one of the Dept. of Defense's needs, namely, the immersive training problem. Immersive training is considered training in which the trainee is provided with an accurately realistic environment that presents them with various situations and challenges to increase their decision making capabilities. In the project presented to the students they must design and create an immersive training vest. Specifically, the vest must provide a means to increase the trainee's knowledge of social interactions with locals of different cultures, with Afghanistan being the culture selected for this project. The training consists of operational tactics, mannerism, and environmental awareness. The cultural differences may be subtle, but can result in a great deal of insults or inappropriate perception by locals.

In the first course the students are given a need statement to guide the development of a set of capabilities to improve the training effectiveness of the immersive training vest. The Missouri $S \& T$ Training Vest platform was initially designed by systems engineering students in the first year of this capstone course program. The vest consists of a Mobile Ad-Hoc Wireless Networked-Mote (MANET-M), a sophisticated electric controller, and vibrating motors for feedback. First, the MANET-M is a wireless communication device developed by Missouri S\&T Electrical Engineering faculty researchers, which has the capability to form wireless communication network through small transceivers called Motes. The Motes are programmed to accept various forms of communications; the ones employed during this project were basic data transfers, which are commonly referred to as "text-messages." The text messages could activate feedback sequences that correspond to turning on-off vibrating motors through the controller. This allows for various feedback sequences to be programmed and deployed to the vest for training purposes. For the current manifestation of the two-capstone course sequence, the two concepts under development are an integrated multi-person location tracking sensor system and an upper-body posture monitoring and recording sensor system.

The courses focus on the introduction of students to systems engineering, familiarizing the students in the multitude of processes undertaken before and during the design activity. The students are given a very general "need statement" developed by the faculty along with Dept. of Defense collaborators to ensure a focus that is relevant to the DoD. This need statement is ambiguous and often lacking in detailed information. The first task presented to the students is to derive the concept that would satisfy the need statement. Hence, the students are tasked with deriving a set of "requirements" and "technical performance measures", which are relevant to the customer. The students complete a series tasks and supply the deliverables in a timely manner. These tasks for the first course are presented in Table 1 below. Similarly, the students in the second course address the tasks and deliverables outlined in Table 2.

Table 1: Systems Engineering 368 Student Tasks

\begin{tabular}{|l|l}
\hline Topic & Students Tasks and Deliverables \\
\hline
\end{tabular}




\begin{tabular}{|c|c|}
\hline Topic & Students Tasks and Deliverables \\
\hline $\begin{array}{l}\text { Requirements / Technical } \\
\text { Performance Measures }\end{array}$ & $\begin{array}{l}\text { - Extract top level requirements from statement of need and stakeholder } \\
\text { interviews. } \\
\text { - Write succinct, quality requirements that in addition to functional needs } \\
\text { address regulatory, health \& safety, and non-functional needs. } \\
\text { - Perform requirement analysis } \\
\text { - Manage requirements, maintain traceability, and demonstrate how } \\
\text { changes in requirements impact systemcost and schedule. }\end{array}$ \\
\hline Architecture Design & $\begin{array}{l}\text { - Develop functions and map the functions to requirements } \\
\text { - Determine systemconcepts that will satisfy thenecessary functions } \\
\text { - Generate system alternatives and establish the feasibility of these } \\
\text { alternatives } \\
\text { - Use decision making methods and tools to select a design to move } \\
\text { forward with }\end{array}$ \\
\hline Risk Assessment & $\begin{array}{l}\text { - Demonstrate an understanding of risk and how it impacts the cost, } \\
\text { schedule, and technological performance of a designed system }\end{array}$ \\
\hline $\begin{array}{l}\text { Technical Management } \\
\text { Plan }\end{array}$ & $\begin{array}{l}\text { - Describe and discuss the necessary management articles necessary to } \\
\text { oversee a complexengineering system } \\
\text { - Plan analys is and design activities, manufacturing operations, integration } \\
\text { and test } \\
\text { - Plan reviews, configuration freezes, verification activities } \\
\text { - Prepare and track performance to budgets } \\
\text { - Create a work breakdown structure that represents the execution of the } \\
\text { systems engineering effort. } \\
\text { - Create and institute a plan to control and track necessary changes to the } \\
\text { systemthroughout development and construction }\end{array}$ \\
\hline $\begin{array}{c}\text { Reliability, Availability, } \\
\& \\
\text { Maintainability }\end{array}$ & $\begin{array}{l}\text { - Create a high level system support plan } \\
\text { - Describe the relationship between reliability and availability } \\
\text { - Describe and contrast maintainability and supportability } \\
\text { - Determine maintainability }\end{array}$ \\
\hline Cost and Schedule & $\begin{array}{l}\text { - Make realistic cost estimates based on system technical requirements } \\
\text { and life-cycle analysis } \\
\text { - Establish a schedule that captures necess ary milestones and deliverables } \\
\text { for project completion }\end{array}$ \\
\hline $\begin{array}{c}\text { Communication } \\
\& \\
\text { Collaboration }\end{array}$ & $\begin{array}{l}\text { - Work with a multi-disciplinary teamto realize theirfinal deliverable } \\
\text { - Conduct review sessions and make presentations that convey their } \\
\text { understanding of the systems engineering process in a clear and concise } \\
\text { manner. }\end{array}$ \\
\hline
\end{tabular}

Table 2: Systems Engineering 468 Student Tasks

\begin{tabular}{|c|l|}
\hline $\begin{array}{c}\text { Synthesis: System } \\
\text { Development and } \\
\text { Physical Integration }\end{array}$ & $\begin{array}{l}\text { - Construct a physical artifact froma provided systemarchitecture } \\
\text { - Manage interfaces between system components requiring multi- } \\
\text { disciplinary expertise }\end{array}$ \\
\hline $\begin{array}{c}\text { Verification and } \\
\text { Validation }\end{array}$ & $\begin{array}{l}\text { - Establish metrics to show that the designed architecture satisfies all } \\
\text { requirements and that the requirements satisfy the customer's need } \\
\text { statement. } \\
\text { - Demonstrate the proposed systemconstructed satisfies customer needs } \\
\text { - Do verification activities } \\
\text { - Do validation reviews with customer representatives }\end{array}$ \\
\hline $\begin{array}{c}\text { Communication \& } \\
\text { Collaboration }\end{array}$ & $\begin{array}{l}\text { - Work with a multi-disciplinary teamto realize theirfinal deliverable } \\
\text { - Conduct review sessions and make presentations that convey their } \\
\text { understanding of the systems engineering process in a clear and concise } \\
\text { manner. }\end{array}$ \\
\hline
\end{tabular}




\section{First Course}

The first course in the capstone sequence is designed to increase the student's capacity to tolerate the inherent ambiguity in the design process, approach design as inquiry or as an iterative loop of divergent-convergent thinking, maintain sight of the big picture by including systems thinking and systems design, and think as part of a team in a social process. These objectives were met through key course activities including, but not limited to, discrete and iterative design analysis and documentation, tracking of multiobjective architecture suitability, and holding designated design reviews.

As the students learned about systems engineering processes and analyses they had to learn not only the discrete steps in performing tasks such as requirements derivation or functional analysis, but the intricacies of the iterative loop of these analysis activities constantly converging towards a final design. Students were seen to initially struggle with the traceability and closed-loop feedback within a system design framework. However, the nature of the parallel team structure successfully forced the students to acclimate themselves to these concepts in order to move their designs forward.

Each week the students worked with their mentors to develop an assessment of six highlevel architecture attributes (performance, risk, schedule, cost, perceptions, facts) as well as their chosen top five qualitative key system attributes. These ratings were presented on Kiviat (star) charts at the weekly faculty meeting. This process enables the students to think about the multi-objective nature and the inherent ambiguity in early system design. This also enabled the students to track their perception of overall system performance as currently specified, providing a beneficial guidepost as to the maturity of their designs.

Each team participated in three design reviews: conceptual design, preliminary design, and detailed design. Each review was a one hour presentation followed by a report submission. Each review milestone was dependent on required list of entry and exit criteria. This review structure serves as a pacing mechanism between the rigid instructional curriculum and the flexible nature of executing the complex group project.

\section{Second Course}

The second course in the capstone sequence is designed to increase the knowledge base of how the student should handle uncertainty, make informative decisions, and think / communicate in several languages of design. Thus, through these main course goals the students were asked to consider their assigned need statement focused the students on developing a sophisticated tracking system capable to integrate to the current system but with a strict budget and timeline of only 5 months. There were a high number of course activities, however, in this discussion only a few will be discussed as examples. These course activities were simulation, optimization, and a domain-focused design revision.

It is through these activities that the students were able to learn not only more effective design but through the employment of system engineering tools and methods. The students were introduced to Monte Carlo, Goal Programming, Preemptive Programming, mathematical modeling, ergonometric design, and many others. The class sought to solve real on-going issues and employed a variety of tools and different areas of engineering. 
The students worked closely in groups and they were asked to assess their team me mbers for contribution at the end of each major assignment. Through simulation the students learned that probability is not arbitrary and can be analyzed to gain insight regarding ambiguity. Through the use of goal programming the students sought to understand how competing objectives can be analyzed and use the information to make better design decisions. The class includes other modules that used decision trees, excel tools (goal seek, table solver, solver, SensIT, and others), DOORs, and many other areas that sought to give the students a variety of tools and methods. Clearly not all tools are necessary but it must be taught how to gather information and use traditional methods of analysis to gain better understanding of often incompletely defined problems.

Each team was given case studies, which sought to employ the tools to solve very specific issues. An example of this was Monte Carlo was used to determine the appropriate placing of the sensors in our system within the operating environment given that the environment would add significant performance reduction. The students had to understand signal fading envelopes, which are traditionally signal processing issues. Furthermore, they had to develop scenarios of movement using distribution functions as well as had to convert physics based models to represent power signal behavior in the ambient environment.

Students were given cases on goal programming, discriminant analysis, regression, time series forecasting, and static simulation. Each topic was covered in a traditional manner, which incorporated lecture and homework assignments from traditional textbook. This allowed the student to familiarize himself or herself with the technical method prior to employing it to the case study.

\section{Course Execution and Results}

The students who currently participate in this program primarily consist of practicing engineers from a variety of engineering disciplines. $83.3 \%$ of students enrolled in these capstone courses during the Fall of 2011 were first-year graduate students, the remainder were second or third year graduate students. $89.5 \%$ were from the Systems Engineering program with the rest from the Engineering Management degree program. $88.9 \%$ of the students reported either currently or previously being employed full-time in a field of engineering, with $57.9 \%$ reporting professional employment as a systems engineer.

A notable aspect of this course structure is the concurrent learning and application approach for the course topics which relies extensively on interdisciplinary team work. Only $52.6 \%$ of the students reported prior participation in engineering course projects as part of an interdisciplinary team.

The students were able to apply newly learned analytical approaches to solving design problems in which they had vested interest and personal history in its development. This has led to very well thought out analysis assignment reports being produced by the students. For example, students were able to provide a discriminant analysis for survey opinions regarding the design approach for the system to derive meaningful comparisons between biases of groups of individuals (students, technical experts, professors, themselves) providing valid and meaningful data towards an actual system design. 


\section{Conclusion}

The concurrent application systems engineering process knowledge in an actual development project has yielded very detailed final design reports from the participants in the first course. These students appear to be motivated by the recognition that the design will be scrutinized by professors and their peers as it will continue to be developed in the second course. Students in the second course, where more complex analytical approaches are learned and applied, come equipped with domain knowledge and vested interest towards the applied exercises to use them as an opportunity further develop their system.

\section{Bibliography}

1 Simon, H.A., The Science of the Artificial, $3^{r d}$ ed., Cambridge, Mass. MIT Press, 1996.

2 Dym, C.L., Agogino, A.M., Eris, O., Frey, D.D., and Leifer, L.J., Engineering Design Thinking, Teaching, and Learning, J. Engineering Education, Jan. 2005.

3 Dutson, A.J., Todd, R.H., Magleby, S.P., and Sorensen, C.D., “A Review of Literature on Teaching Design Through Project-Oriented Capstone Courses," Journal of Engineering Education, Vol. 76, No. 1, 1997, pp. 17-28.

4 Sams on, C.H. and Lowery L.L., "The need for systems engineering education," Proc. of the National Council on Systems Engineering, Arlington, Virginia, July 26-28, 1993.

5 Sage A.P., "Systems Engineering Education," IEEE Trans. on Systems, Man, and Cybernetics Part C Applications and Reviews, Vol.30, No. 2, May 2000. 